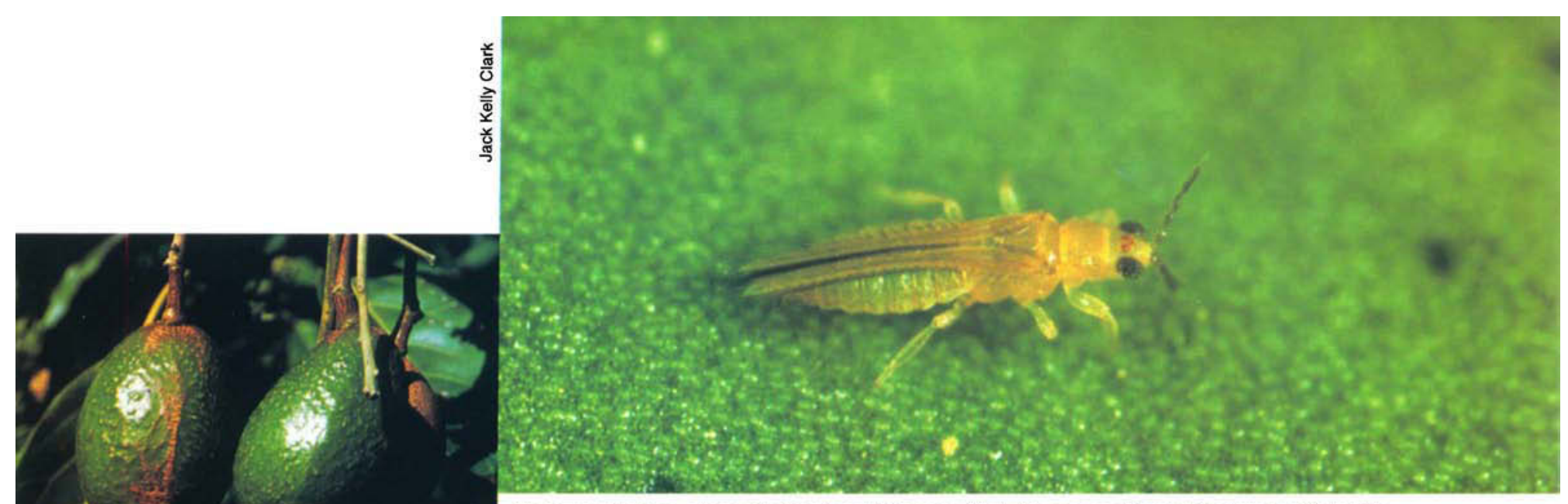

Avocado thrips, above (adult female), were first discovered in California in 1996. They have since become a major pest, with $80 \%$ of commercial orchards reportedly spraying to control them. On maturing fruit, left, avocado thrips cause elongate feeding scars.

\title{
Avocado thrips: New challenge for growers
}

\author{
Mark S. Hoddle
}

\author{
Joseph G. Morse
}

\author{
- Phil A. Phillips
}

A vocado thrips is a new pest of major economic significance in California avocado orchards. This insect was first discovered on avocados in June 1996, near Port Hueneme in Southern California. Soon afterward, populations damaging fruit and foliage were discovered in Saticoy and Oxnard, Ventura County, and in orchards in Irvine, Orange County. By July 1997, infestations of avocado thrips had spread north into San Luis Obispo County and south into San Diego County. Heavily infested orchards in Ventura County experienced $50 \%$ to $80 \%$ crop damage in 1997, and much of the fruit was either unmarketable or was downgraded in packinghouses. California is the only state in which avocado thrips have been reported as a major pest; they currently infest $95 \%$ of the state's 59,000 avocado acres. Approximately $80 \%$ of commercial orchards require pesticide applications to control this pest.

Avocado thrips was previously an undescribed species, and its country of origin was not known at the time of its discovery in California. Taxonomic work by Dr. S. Nakahara with the U.S. Department of Agriculture/Agricultural Research Service's Systematics Laboratory produced the official scien-
Ben A. Faber Karen M. Jetter tific name, Scirtothrips perseae (Thysanoptera: Thripidae)(Nakahara 1997). The recommended common name is avocado thrips. Morphological comparisons have determined that avocado thrips is more closely related to Scirtothrips species in Central America than to Scirtothrips species (for example, citrus thrips, Scirtothrips citri) in North America. Furthermore, in 1971, undescribed specimens of Scirtothrips were found on smuggled avocados from Oaxaca, Mexico, at the Port of San Diego. These specimens, morphologically very similar to $S$. perseae, are considered to be the same species.

Avocado thrips are small, slender, yellow-colored insects that are about one-sixteenth inch in length. Adults are winged but are poor fliers, and females lay eggs inside immature leaves and fruit about 1 to 2 inches long. Thrips larvae and adults can build up to such high densities on young leaves during the spring that subsequent feeding damage can cause premature leaf drop. The main source of economic loss attributable to avocado thrips is scarring of immature fruit in late spring by larvae and adults. Scarring can be severe enough to render the entire fruit surface brown, and a 
Potential avocado pests and biological controls, identified in foreign exploration:

Phytophagous thrips species:

Caliothrips phaseoli

Frankliniella bruneri

F. brunnea, F. cephalica, F. chamulae, F. condei,
F. cubensis, F. fallaciosa, F. gardeniae, F. gemina.

F. cubensis, F. fallaciosa, F. gardeniae, F. gemina,
F. gossypiana, F. occidentalis, F. parvula

F. rodeos, F. schultzel, F. williams

Leucothrips furcatus

Neohydatothrips burungae

N. geminus, N. tibialis

Pseudophilothrips perseae

Scirtothrips aceri

S. citri, S. inermis, S. lumarius

Selonothrips rubrocinctus

Predator thrips (potential biological controls):

Franklinothrips orizabensis,

Leptothrips mcconnelli

Scolothrips pallidus

characteristic "alligator skin" appearance results. Fruit that are entirely scarred can continue to grow, and the flesh of the fruit is a healthy green. However, even partial fruit scarring results in downgrading in packinghouses because of cosmetic damage.

\section{Natural enemies}

In order to identify host-specific natural enemies that are climatically preadapted to California and successfully establish biological control of this pest, it is essential to determine the geographic distribution of avocado thrips in its native habitat. Our host-plant surveys in California indicate that avocado thrips feeds and reproduces only on avocados. We suspect that the natural range of this pest is closely correlated with the centers of origin of the host plant. Three distinguishable ecological races or subspecies of avocado (Perseae americana) are recognized: (1) Mexican (P. americana var. drymifolia), (2) Guatemalan ( $P$. americana var. guatemalensis) and (3) West Indian or Caribbean

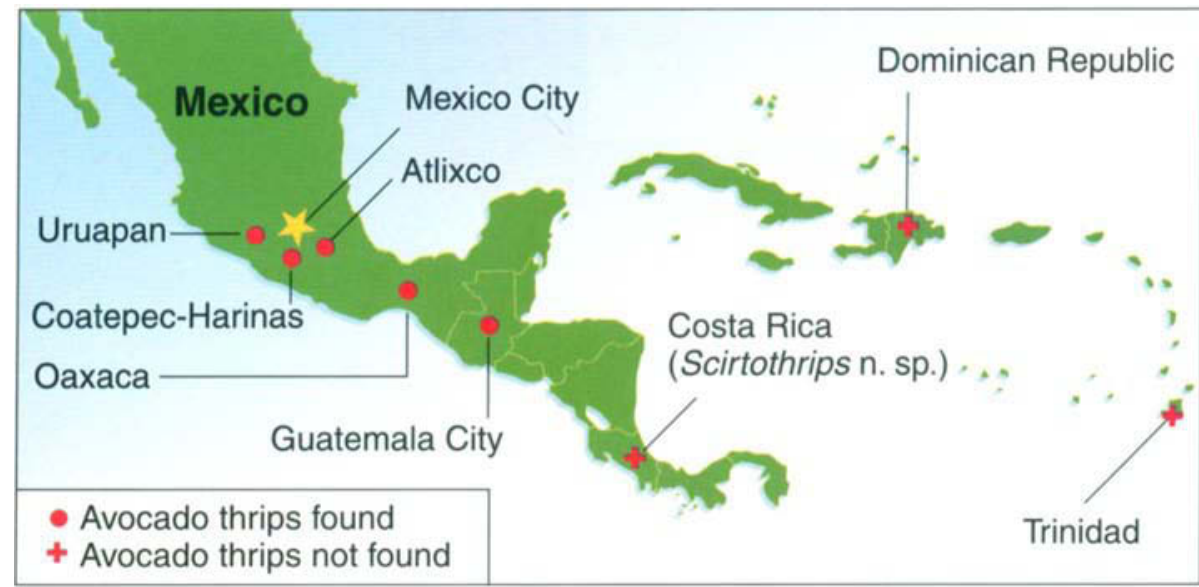

Fig. 1. Locations of foreign exploration for avocado thrips (Scirtothrips perseae) in Mexico and Central America.

(P. americana var. americana) types (Scora and Bergh 1990). We have explored the areas of origin of these avocado races for avocado thrips.

Foreign exploration for avocado thrips and natural enemies was completed in Mexico (Atlixco, CoatepecHarinas, Oaxaca, Uruapan and the Yucatan), Guatemala (around Guatemala City and Antigua), Costa Rica (orchards around San José), the Caribbean (Dominican Republic and Trinidad) and Brazil. We have received considerable assistance from Mexican and Central American colleagues who helped us locate backyard and roadside plants, as well as trees in abandoned and commercial orchards, to sample for avocado thrips and associated natural enemies. Foreign exploration efforts have located avocado thrips only in Mexico and Guatemala (fig. 1). The most common natural enemies associated with avocado thrips in Mexico and Central America are predatory thrips belonging to the genera Franklinothrips and Leptothrips.

Foreign exploration allowed us to compile a list of other thrips (47 species in 19 genera) that are not presently established in California but that could become serious avocado pests if they arrive here (see box). One species, Neohydatothrips burungae, is as common as avocado thrips on avocados in Mexico but is not known to be present in California. Given the common occurrence of S. perseae in Mexico and Guatemala on avocados and its pestiferous nature in
California, N. burungae could also pose a threat to California avocado growers if it became established.

\section{Progress toward IPM}

\section{Densities, fruit size, economic} scarring. Young fruit are vulnerable to avocado thrips feeding damage. As young foliage from the spring growth hardens during the time of fruit set (late May and early June), adult female avocado thrips move from the foliage to oviposit into young fruit. Feeding by the emerged larvae results in damage to the skin of developing fruit. Laboratory observation of fieldcollected fruit indicates that females lay eggs in fruit ranging from 0.16 to 3.0 inches in length. The majority of larvae (more than 95\%) emerged from fruit ranging from 0.59 to 2.5 inches in length, with the highest numbers emerging from fruit 1.5 to 1.75 inches in length. Once fruit exceed 2 inches in length, avocado thrips are found primarily on young leaves.

Field biology studies conducted over 3 years, at three sites with different temperatures in Ventura and Santa Barbara counties, indicated that fruit are most susceptible to damage over a 2-week growing period just after fruit set, when fruit are 0.2 to 0.6 inches in length. These studies also indicated that when approximately three to five thrips were consistently found per leaf during fruit set, feeding caused $6 \%$ to $15 \%$ economic scarring damage on fruit. Furthermore, young fruit 0.5 inches long or less that were infested with an average of 0.5 to 1.5 larvae per 
fruit in May and June resulted in 22\% to $51 \%$ economic scarring.

In all years and sites, thrips were generally more abundant on young leaves than on fruit from early to midJune when fruit were setting. When leaves aged and hardened from late June through August, equal or higher numbers of thrips were generally found on fruit, although overall numbers of thrips declined during this period with increasing summer temperatures (Yee at al. 2001).

Our results suggest that thrips numbers on leaves prior to or during damage on fruit, and that the economic injury level may be less than five larvae per leaf during this time. Because low numbers of larvae on fruit in the sensitive 2-week postfruit-set period can result in high levels of scarring, early insecticide treatments when thrips are on leaves, but before they move onto fruit, may help prevent damage to fruit. Many avocado orchards are located on rugged, hilly terrain that can be sprayed only by helicopter. For those orchards, earlier, pre-fruit-set treatments may be especially important. Furthermore, the small window of opportunity for treatment during fruit set can create insecticide application scheduling problems resulting in delayed or missed applications and significant fruit damage.

Spray trials, resistance monitoring. Avocado pest management in fruit set can be used to predict scarring

California has historically relied on biological control with minimal use of pesticides. As avocado thrips became a serious problem in California, our initial response was to search for selective pesticides (that is, those with minimal impact on beneficial biological control agents) that might help alleviate the problem until longer-term research could identify nonchemical solutions for managing avocado thrips. Because avocado thrips is taxonomically related to citrus thrips (both are in the genus Scirtothrips), we borrowed heavily from past research done with citrus thrips on citrus.

Laboratory and field pesticide efficacy studies conducted on avocados in San Diego and Ventura counties identified three pesticides as being both efficacious and relatively selective: sabadilla (Veratran D, Dunhill Chemical Co.), abamectin (Agri-Mek, Syngenta) and spinosad (Success, Dow AgroSciences). With the assistance of the companies producing these materials, the California Avocado Commission, and the California Department of Pesticide Regulation, we worked toward making all three pesticides available for use by avocado growers so that the materials could be used in rotation to avoid the development of pesticide resistance (historically a serious problem with pestiferous thrips species).

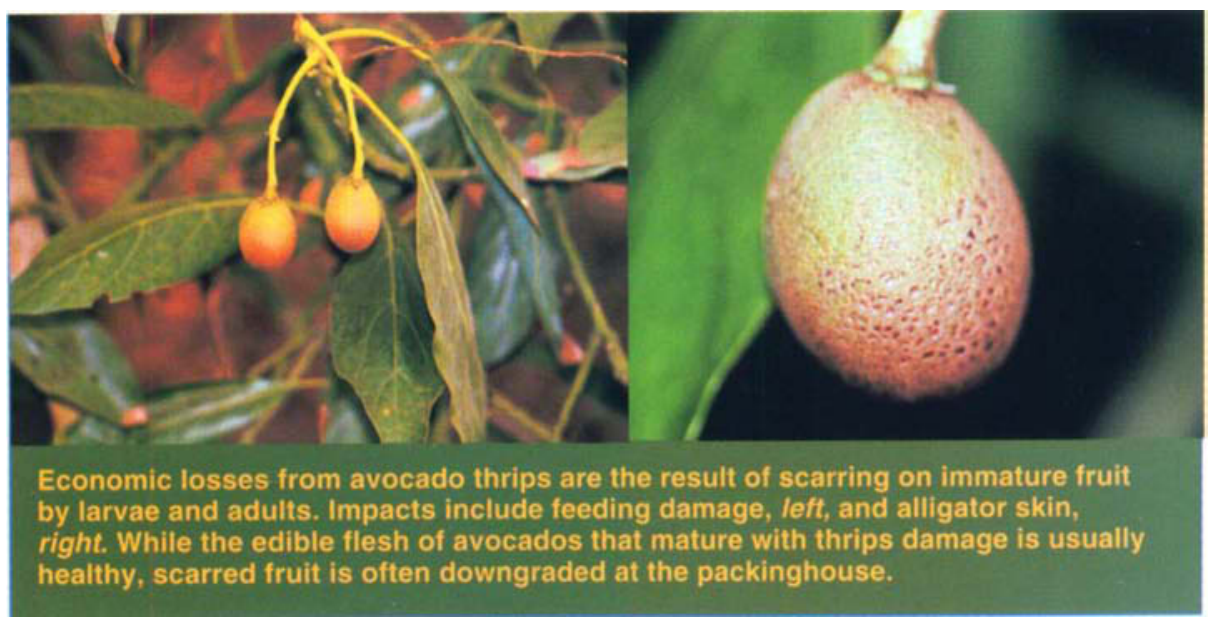

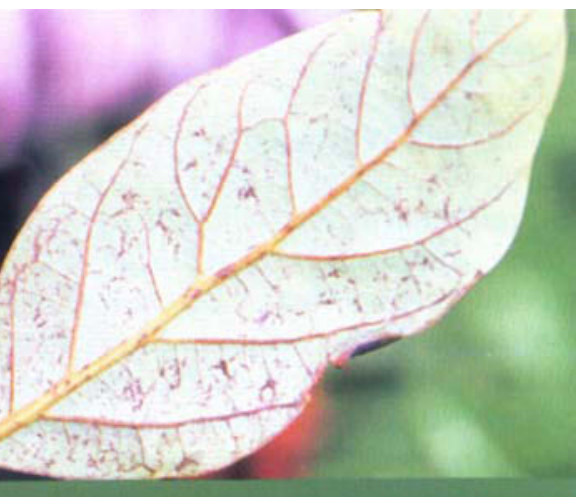

While individually quite small, avocado thrips can build up at such high densities on young leaves that premature leaf drop occurs. Larval and adult feeding damage is concentrated along the midrib and between veins on the leaf's underside.

Sabadilla was the first pesticide to be made available for control of avocado thrips under a Special Local Needs (24C) permit in 1997 and was fully registered in 1998. Abamectin was made available in 1999, 2000 and 2001 under a Section 18 Emergency Exemption, and spinosad was registered for use on avocados in 2000 . Before each pesticide was made available, we initiated baseline pesticide resistance monitoring to determine the inherent susceptibility of avocado thrips to each material. Using these data, any future cases of low field efficacy can be evaluated to determine whether the avocado thrips are actually developing resistance to the product, or whether there are other causes, such as severe population pressure, poor timing of treatment or improper application (Phillips et al. 2000). Resistance development to sabadilla by some avocado thrips populations has been identified in some orchards that have used this insecticide multiple times in one season.

Cultural and biological control. Combined field and laboratory studies indicate that approximately $77 \%$ of $S$. perseae larvae drop from avocado trees to pupate in the upper 2 inches of leaf duff beneath the tree canopy, before emerging as winged adults that fly back up into the canopy to commence feeding and reproduction. One strategy for increasing thrips pupation mortality rates beneath trees is to use composted organic yard waste for control of avocado root rot (Phytophthora 
cinnamomi). We are currently investigating this strategy.

Preliminary data indicate that coarse, composted mulch placed around trees and over existing leaf mulch to a depth of about 12 inches and spread to the edge of the canopy can reduce peak emergence rates of adult $S$. perseae by approximately $50 \%$ in comparison to emergence rates from naturally occurring leaf duff under avocado trees that lack mulch (fig. 2). The exact mechanism that causes reduced adult thrips emergence from mulch is not known at this time but may be due to antagonistic microarthropods associated with the mulch; release of secondary plant compounds from decaying yard waste; or a more favorable habitat for entomopathogens such as fungi (for example, Beauveria spp.) or nematodes (for example,

Steinermema spp.) that we have recovered from the mulch. We are continuing to work on mulches and on determining the mechanisms responsible for suppressing avocado thrips.

We are also studying a second noninsecticide strategy for controlling $S$. perseae, the use of augmentative releases of mass-reared Franklinothrips orizabensis. This native predatory thrips is the key natural enemy associated with $S$. perseae in California avocado orchards.

Preliminary trials of releasing massreared $F$. orizabensis that were shipped from a commercial insectary in Europe were not successful in controlling S. perseae. One major problem with this experiment was the poor quality of adult predators after shipping; more than $50 \%$ of aspirated and shipped adults died in transit, and the survivors were of marginal health (Silvers 2000). Therefore, we decided to mass-rear this predator in California. We evaluated 10 diets from commercially available food items to determine their suitability. The best diet tested was irradiated Ephestia kuehniella eggs (used for massrearing Trichogramma) combined with Tetranychus pacificus eggs (used for mass-rearing predatory phytoseiid mites)(Hoddle, Jones et al. 2001).
To reduce handling and transit mortality, we developed a harvesting technology that uses clear plastic tubes to collect pupating predators.

Franklinothrips larvae spin silk pupation cocoons in the tubes, which are easy to harvest and protect pupating predators from damage during shipping. In shipping trials, this technique reduced predator mortality rates to $2 \%$ to $3 \%$. In comparison, more than $50 \%$ mortality results from shipping aspirated adult $F$. orizabensis (Hoddle, Oishi et al. 2001). This mass-rearing and harvesting technology has been extended to two commercial California insectaries, and large-scale field trials are currently under way in Ventura and San Diego counties with locally reared F. orizabensis.

\section{Economic impacts on production}

Economic losses to growers experiencing an avocado thrips infestation arise from a reduction in fruit quality due to scarring and from increased pest control costs. Scarred Grade A quality fruit are reduced to standard grade or are culled entirely, while some packinghouses have papacado grades for heavily scarred fruit. With lower prices for standards, grower revenues decrease as a larger share of fruit falls into this category. Using packinghouse data, the amount of fruit downgraded due to an untreated thrips infestation can be as high as $95 \%$. On average, losses due to thrips damage reduced revenues by $12 \%$ in 1998 (CAC 1998).

In an attempt to prevent large losses in revenue, growers may treat groves with one of the three insecticides recommended for use against avocado thrips. During 2001, abamectin was the most commonly used insecticide, followed by spinosad, then sabadilla. Usually, growers used only one application of an insecticide to control avocado thrips. If they made more than one application, it was typically different from the first insecticide sprayed. As recommended by IPM professionals, insecticides are alternated to prevent the development of pesticide resistance in avocado thrips.

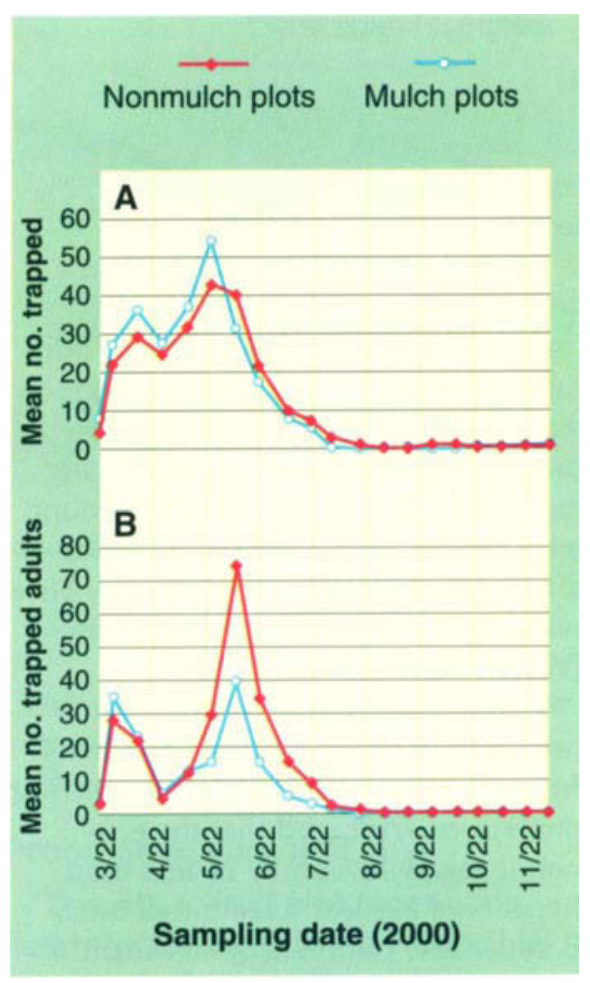

Fig. 2. Mean numbers of (A) avocado thrips larvae trapped on tops of clear sticky panels in thrips emergence boxes, after they fall out of tree canopy to pupate, and (B) mean numbers of adult thrips trapped on undersides of clear sticky panels in thrips emergence boxes, following emergence from composted mulch or leaf duff.

The control costs reported in this study were those incurred by a typical California avocado grower in 2001. Individual costs vary depending on the grower's situation. Abamectin was usually applied to avocados by helicopter with $1 \%$ to $2 \%$ NR-415 oil added to move the insecticide into the leaf. The total cost of the insecticide, oil and application was approximately $\$ 180$ per acre per treatment. Treating avocado thrips eliminates economic damage for some growers, but only reduces the level of severity for others. With insecticide treatments, revenue losses from reduced fruit quality were approximately 3\% (CAC 1998). Using a 3-year (1994 through 1997) average for grower revenues before avocado thrips infestations occurred, downgrading reduced revenues by an estimated $\$ 145$ per acre after the pest became established in California. The total increase in grower costs was 


\section{"The establishment of exotic species in California agro-ecosystems weakens implemented IPM programs ..."}

equal to treatment costs ( $\$ 180$ per acre) plus losses associated with downgrading ( $\$ 145$ per acre), for a total of $\$ 325$ per acre. Based on budgets developed by UC Cooperative Extension and the California Avocado Commission, grower costs increased by about $8 \%$ with avocado thrips populations that required management (USDA 1999).

The impact on the avocado industry depends on the extent of the thrips infestation and grower adjustments to the infestation over time. Not all growers will have an avocado thrips infestation that causes economic losses. Growers within 10 miles of the coast were more likely to suffer problems than growers farther inland, where the marine influence does not moderate the hot summer temperatures that cause pest population crashes. To the extent that higher costs are passed on to consumers, growers without an infestation of avocado thrips are better off, because they receive higher prices without incurring higher production costs.

It takes time for an industry to adjust to a new exotic pest problem. Therefore, short-run losses are greater than losses over the long term, after growers adjust to changes in cost and market prices. In the short run, the annual cost of avocado thrips to the avocado industry is estimated to be $\$ 12$ million to $\$ 14$ million. In the long run, it is estimated at $\$ 8$ million to $\$ 11$ million per year.

\section{Managing a new exotic pest}

The establishment of exotic species in California agro-ecosystems weakens implemented IPM programs and requires agricultural industries to rapidly develop or modify and adopt new IPM programs to manage new invasive pests within the context of existing pest complexes. Our work in developing an IPM program for avocado thrips in California is multifaceted, consisting of several concurrent research programs that have simultaneously investigated biological, cultural and chemical control. Economic analyses have quantified the detrimental fiscal impact of avocado thrips on avocado production in California. The rapid deployment of cooperative research and extension efforts, composed jointly of industry support, UC Agricultural Experiment Station personnel and Cooperative Extension personnel, has allowed the development of an IPM program to meet a new pest challenge facing California's 6,000 avocado growers.

Work is continuing on identifying natural enemies of avocado thrips in its home range for possible importation into California. We will be investigating the effect that pruning schedules and fertilizer applications

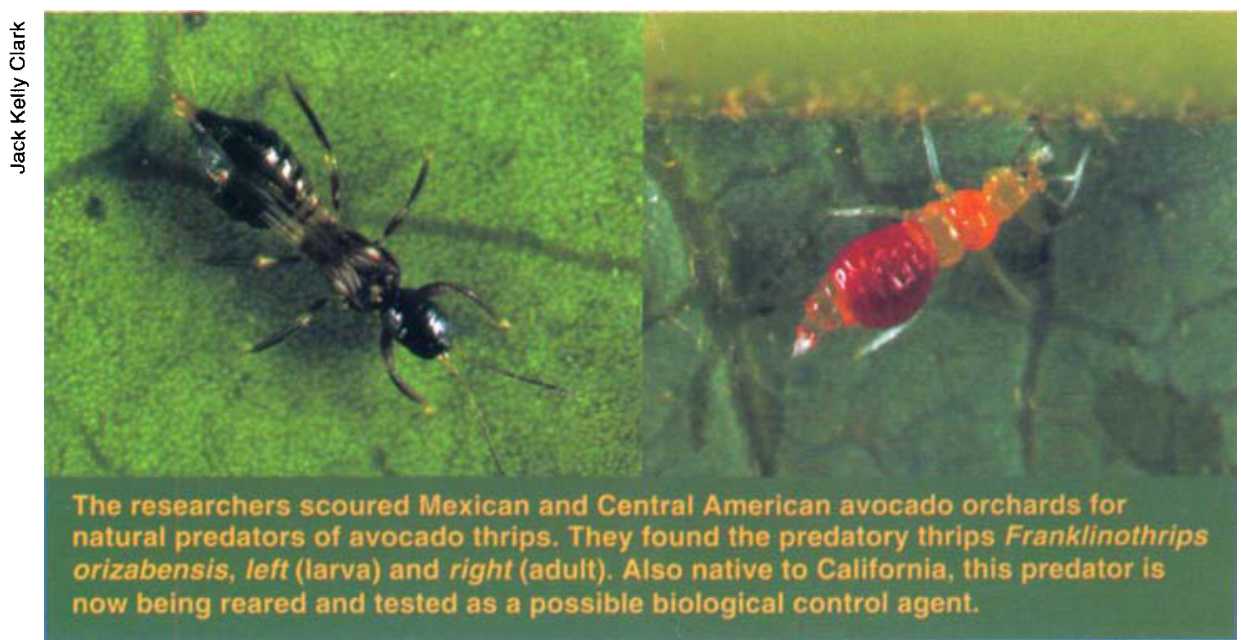

have on flush and fruit-setting patterns and subsequent thrips damage to developing fruit. Cultural manipulations combined with natural enemies and carefully timed applications of selective insecticides may reduce grower reliance on pesticides for controlling avocado thrips, thereby promoting sustainable avocado production in California.

M.S. Hoddle is Biological Control Extension Specialist and J.G. Morse is Professor of Entomology, UC Riverside; P.A.

Phillips is Area IPM Advisor and B.A. Faber is Farm Advisor, UC Cooperative Extension, Ventura County; and K.M. Jetter is Agricultural Economist, Agricultural Issues Center at UC Davis.

\section{References}

[CAC] California Avocado Commission. 1998. Agricultural Advisory Policy Study Field Data Collection Report. Santa Ana, CA.

Hoddle MS, Jones J, Oishi K, et al. 2001. Evaluation of diets for the development and reproduction of Franklinothrips orizabensis (Thysanoptera: Aeolothripidae). Bull Entomol Res 91:273-80.

Hoddle MS, Oishi K, Morgan D. 2001. Pupation biology Franklinothrips orizabensis (Thysanoptera: Aeolothripidae) and harvesting and shipping of this predator. Fla Entomol 84:272-81.

Nakahara S. 1997. Scirtothrips perseae (Thysanoptera: Thripidae), a new species infesting avocado in southern California. Insecta Mundi 11:189-92.

Phillips PA, Yee WL, Morse JG, Hoddle MS. 2000. An update on management of the avocado thrips. Cal Avocado Soc Newsletter, Spring 2000 .

Scora RW, Bergh B. 1990. The origins and taxonomy of avocado (Persea americana) Mill. Lauraceae. Acta Horticulturae 275:387-94.

Silvers C. 2000 . Biological control of Scirtothrips perseae Nakahara in California avocados: Assessment of two generalist predators. M.S. thesis, UC Riverside. 103 p.

[USDA] US Department of Agriculture. 1999. Fruit and Nut Situation and Outlook Yearbook. Market and Trade Economics Division, Economic Research Service. FTS-290.

Yee WL, Phillips PA, Faber BA, Rodgers JL. 2001. Relationships between Scirtothrips perseae (Thysanoptera: Thripidae) populations on avocado leaves, fruit and scarring damage on fruit. Environ Entomol 30:932-8. 